\title{
Theory of bulk and flow electrolysis and approach to parameter optimisation for chromatographic electrochemical detection
}

\author{
O. Abollino*, M.C. Bruzzoniti, E. Mentasti and C. Sarzanini \\ Department of Analytical Chemistry, University of Torino, Via P. Giuria 5, 10125 Torino, Italy
}

\begin{abstract}
The performance and characteristics of an amperometric-coulometric detector for liquid chromatography were investigated as a function of the main chromatographic parameters. Hydroquinone was chosen as reference compound. Starting from the theory of bulk and flow electrolysis, the effect of eluent flow rate on the detector response was investigated and the agreement between experimental and calculated data was verified. The study was preceded by an investigation of the detector behaviour in different chromato graphic operating conditions: void volume evaluation, effect of mobile phase composition on baseline behaviour, current/potential curve for analyte and mobile phase, analyte stability, linearity, repeatability of the detector response and electrochemical exclusion from interferences were examined.
\end{abstract}

Key words. Electrochemical detection — liquid chromato graphy — electrolysis — hydroquinone — catechol.

\section{Introduction}

Electrochemical (coulometric and amperometric) detection in chromatography is known to have several advantages such as high sensitivity, wide linear range, the possibility to distinguish among different oxidation states of the same analyte and the applicability to a wide range of electroactive solutes [1], from organic substances (e.g. amines, phenols, mercaptans, aromatic nitro and halogen compounds, aldehydes and ketones) [2-5] to inorganic ones (anions and cations) [6-7]. Nowadays electrochemical detection is extensively adopted in biochemistry for organic analytes (sugars, peptides, catecholamines, vitamins, drugs...) [8-12]; it is also employed for environmental analysis of organic contaminants (phenols, pesticides...) [13-14], whereas it is less commonly applied to metal ion determination [15-16].

Though this extensive use of electrochemical detection for applicative purposes, in no case in the current literature has the behaviour of an electrochemical detector been studied as a function of mobile phase parameters especially in particular chromatographic mechanisms such as ion pair chromatography. The knowledge of such behaviour is important to optimise electrochemical detection after chromatographic separation. Thus in this work several parameters related to analyte detection after HPLC separation, were investigated and the results obtained are reported hereafter. In particular hydroquinone was chosen as a reference solute since its chromatographic retention and redox mechanism are well known.

The paper consists of two sections. In the first one (detector characterisation) the behaviour and performance of the detector are described: the results obtained can be of practical use in order to establish the operative conditions also for the detection of other analytes. The second section (bulk and flow electrolysis) deals with the effect of flow rate on the chromatographic signal. The process occurring in the detector cell in the presence of an electroactive species is actually an electrolysis. Therefore, starting from the theory of bulk and flow electrolysis, a model for predicting the detector response as a function of eluent flow rate was applied and its agreement with experimental results was compared.

\section{Materials and methods}

The chromatographic system used was a Gilson Model 302 pump fitted with a Gilson Model 208 manometric module, a Rheodyne Model 7125 injection valve with a $100 \mu \mathrm{L}$ loop, an ESA Coulochem 2 amperometric/coulometric detector equipped with an ESA electrolysis cell Model 5011.

The cell was equipped with two porous graphite working electrodes, each coupled with a platinum counter electrode and a palladium reference electrode, enclosed in two stainless steel chambers. The cell volume was $5 \mu \mathrm{L}$.

The analytical column was a Merck Lichrospher 100 RP$18(250 \times 4 \mathrm{~mm}$ i.d.) coupled to a Merck LichroCART 4-4 $(4 \times 4 \mathrm{~mm}$ i.d.) guard column.

$100 \mu \mathrm{L}$ aliquots were injected. The flow rate was $1.0 \mathrm{~mL} / \mathrm{min}$.

The void volume of the chromatographic system was measured by injection of a $100 \mu \mathrm{L}$ sample of $200 \mu \mathrm{g} \mathrm{L}^{-1} \mathrm{Fe}$ (II) obtained by dilution of a concentrated $1000 \mathrm{mg} \mathrm{L}^{-1}$ ferrous sulphate solution.

The chromatograms were recorded on a personal computer with the aid of a dedicated software (Dionex AI-450) which allows peak area integration.

An Orion EA-920 pH meter equipped with a combined glass-calomel electrode was used for $\mathrm{pH}$ measurements. 
Reagent volumes were measured with Eppendorf and Gilson pipettes.

High purity water (HPW) obtained from a Milli-Q system (Millipore) was used throughout.

Chromatographic grade methanol (Carlo Erba) was used. The other chemicals were analytical grade reagents. Tetrabutylammonium (TBA) chloride and sodium formate were purchased from Fluka. Sodium chloride, nitric acid and ferrous sulphate were obtained from Carlo Erba. Acetic acid, sodium acetate, sodium hydroxide, 1,4- and 1,2-dihydroxybenzene (hydroquinone and catechol) were Merck products.

$1000 \mathrm{mg} \mathrm{L}^{-1}$ hydroquinone and catechol stock solutions were obtained by dissolving $0.100 \mathrm{~g}$ of solid compound in $100 \mathrm{~mL}$ of methanol and stored in the dark. Test solutions were then prepared daily by dilution with mobile phase.

Acetic acid/sodium acetate $(\mathrm{pH} 4.75$ and 5.50) and sodium formate ( $\mathrm{pH} 3.75)$ buffer solutions were employed.

The eluents were water-methanol mixtures buffered at the proper $\mathrm{pH}$ and added with TBA chloride and $\mathrm{NaCl}$ when required (see below).

All solutions (samples and mobile phases) were vacuumfiltered through Millipore $0.22 \mu \mathrm{m}$ cellulose ester filters and degassed with Ar. A continuous purging of the eluent during the chromatographic run was found to provide a lower noise. A 10 minutes degassing time before starting experiments is enough in the presence of higher analyte concentrations, when the noise can be neglected.

The detector was kept turned on overnight with the mobile phase flowing through it at $0.1 \mathrm{~mL} / \mathrm{min}$ in order to condition the cell. The eluent was recirculated in order to reduce reagent consumption and avoid electrode fouling.

The column was periodically cleaned with watermethanol mixtures containing increasing methanol percentages. The treatment with a high water content solution allows to remove traces of salts possibly precipitated in the column, whereas the increasing methanol concentrations ensure the elution of strongly retained organic substances.

The cell was usually cleaned by simply flowing pure methanol. The capacity factors for hydroquinone ranged between 0.6 and 1.3 depending on the mobile phase composition, decreasing with increasing methanol and buffer percentage.

\section{Results and discussion}

\section{Detector characterisation}

In order to characterise the features and performance of the detector in a HPLC separation, the behaviour of hydroquinone was studied as a reference analyte. The results obtained are strictly dependent on the chromatographic system and on the solute, but provide indications about the detector capabilities (e.g. linearity, repeatability, interference exclusion) and its correct use (e.g. baseline stabilisation). The following parameters were investigated:

- void volume evaluation: its determination is important for a correct characterisation of the chromatographic behaviour of an analyte in different chromatographic conditions (e.g. different columns and mobile phase compositions). Using such a sensitive detector, the value of the void volume could not be identified by simply injecting water, as it usually happens with other detection systems (e.g. direct or indirect spectrophotometry), since an irregular baseline was obtained with more than one small signals, probably due to a perturbation of the mobile phase composition (in order to avoid this drawback, during the other experiments the analytes are diluted in the eluent, and a stabilisation of the system is required whenever some parameter is changed, as shown in the next section) and to residual impurities in water. Therefore an electroactive solute unretained by the $\mathrm{C}_{-18}$ column was utilised. Injection of sulphide ions $\left(2.0 \mathrm{mg} \mathrm{L}^{-1}\right)$ did not give the expected results since $\mathrm{S}^{-}$was partially retained by the sorbent and gave rise to a peak close to the one of hydroquinone with the mobile phases studied. Among other candidates $\mathrm{Fe}(\mathrm{II})$ proved the best choice. In fact, with the eluent employed $\left(\mathrm{H}_{2} \mathrm{O}-\mathrm{CH}_{3} \mathrm{OH} 85 / 15\right.$ containing $100 \mathrm{mM}$ $\mathrm{CH}_{3} \mathrm{COOH} / \mathrm{CH}_{3} \mathrm{COONa}, \mathrm{pH} 4.75$ ), it was not retained by the column and allowed to detect the void volume as $2.2 \mathrm{~min}$ (oxidation potential $500 \mathrm{mV}$ ); a $200 \mu \mathrm{g} \mathrm{L}^{-1}$ solution was used for this purpose. This species appears convenient for a proper determination of void volume of a RP column coupled with an amperometric detector;

- baseline behaviour: it is well known that the instrumental baseline must be as low and constant as possible in order to get reproducible results and low detection limits for reliable quantitative determinations. Therefore the effect of various mobile phase parameters on the intensity and stability of the background signal was investigated.

The main applications of HPLC are the typical reversed phase (RP-HPLC) [17] and ion interaction chromatography (IIC) [18] separations. In view of coupling the electrochemical detection with both RP-HPLC and IIC mechanisms, some typical mobile phase compositions were investigated, studying the effect of various parameters on the intensity and stability of the background signal. Figure 1A reports the background current vs. applied potential for different mobile phases $\left(\mathrm{H}_{2} \mathrm{O} / \mathrm{CH}_{3} \mathrm{OH} 85 / 15\right.$ (v/v) containing $85 \mathrm{mM} \mathrm{CH} \mathrm{COOH}_{3} \mathrm{CH}_{3} \mathrm{COONa}, \mathrm{pH} 5.5$; $\mathrm{H}_{2} \mathrm{O} / \mathrm{CH}_{3} \mathrm{OH} 40 / 60(\mathrm{v} / \mathrm{v})$ containing $20 \mathrm{mM} \mathrm{CH} \mathrm{CHOH}_{3} \mathrm{COO}$ $\mathrm{CH}_{3} \mathrm{COONa}, \mathrm{pH} 5.5,10 \mathrm{mM}$ TBACl, $30 \mathrm{mM} \mathrm{NaCl}$; $\mathrm{H}_{2} \mathrm{O} / \mathrm{CH}_{3} \mathrm{OH} 40 / 60$ (v/v) containing $20 \mathrm{mM}$ formate, $\mathrm{pH}$ $3.75,10 \mathrm{mM}$ TBACl, $30 \mathrm{mM} \mathrm{NaCl}$ ). The last two eluents contained a typical ion-pairing agent (TBACl) and ionic strength modifier $(\mathrm{NaCl})$ commonly employed in ion-pair separations [18].

The figure shows that the signal slowly increases from 150 to $800 \mathrm{mV}$, then it grows exponentially up to $900 \mathrm{mV}$. Higher values were not tested because in common practice it is advisable to operate between -1000 and $900 \mathrm{mV}$ in order to extend cell lifetime.

The current increase with potential depends on the mobile phase composition and is more relevant for acetate based buffers, whereas formate buffer gives rise to a lower noise than acetate at equal concentration. Their different behaviour could be due to the different dissociation degrees of the acidic forms of the buffers (it has been calculated that the actual acetate ion concentration in water is $17 \mathrm{mM}$ 

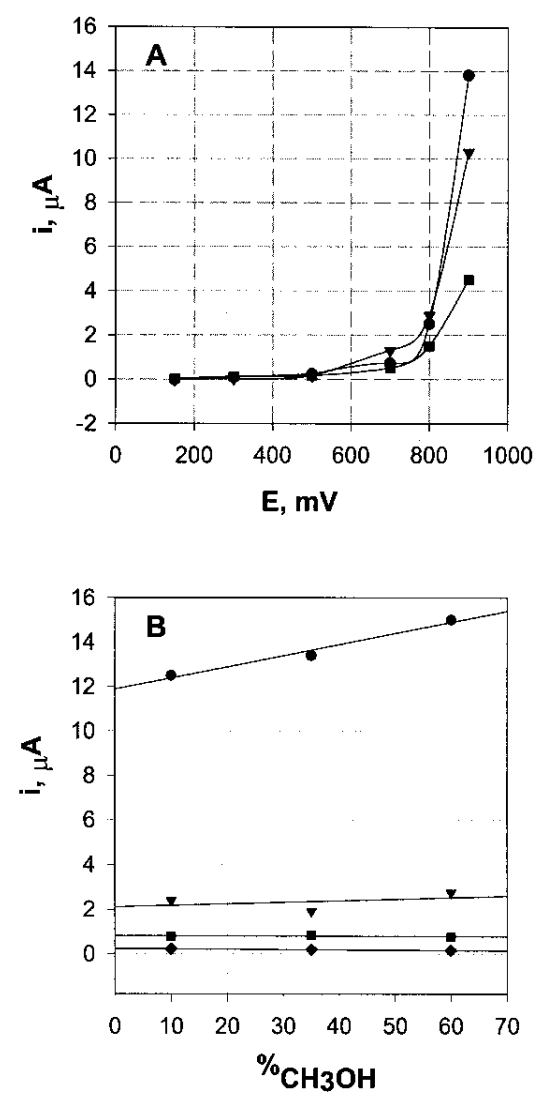

Fig. 1. Background current behaviour. A) effect of detection potential. Mobile phases: $\mathrm{H}_{2} \mathrm{O} / \mathrm{CH}_{3} \mathrm{OH} 85 / 15$ (v/v) containing $85 \mathrm{mM}$ $\mathrm{CH}_{3} \mathrm{COOH} / \mathrm{CH}_{3} \mathrm{COONa}$, pH $5.5(\bullet) ; \mathrm{H}_{2} \mathrm{O} / \mathrm{CH}_{3} \mathrm{OH} 40 / 60$ (v/v) containing $20 \mathrm{mM} \mathrm{CH} \mathrm{CHOOH}_{3} \mathrm{CH}_{3} \mathrm{COONa}, \mathrm{pH} 5.5,10 \mathrm{mM} \mathrm{TBACl}$, $30 \mathrm{mM} \mathrm{NaCl}(\boldsymbol{\nabla}) ; \mathrm{H}_{2} \mathrm{O} / \mathrm{CH}_{3} \mathrm{OH} 40 / 60$ (v/v) containing $20 \mathrm{mM}$ formate, $\mathrm{pH} 3.75,10 \mathrm{mM}$ TBACl, $30 \mathrm{mM} \mathrm{NaCl}(\mathbf{\square})$; B) effect of methanol percentage. Mobile phase containing $90 \mathrm{mM}$ $\mathrm{CH}_{3} \mathrm{COOH} / \mathrm{CH}_{3} \mathrm{COONa}$, pH 5.5. Oxidation potentials: $500 \mathrm{mV}$ $(\bullet), 700 \mathrm{mV}(\mathbf{\square}), 800 \mathrm{mV}(\boldsymbol{\nabla}), 900 \mathrm{mV}(\bullet)$.

against $10 \mathrm{mM}$ formate ion) and to the different $\mathrm{pK}_{\mathrm{a}}$ values in the presence of organic solvents.

As expected the baseline signal was found to increase with buffer concentration, mainly due to the presence of more trace impurities, this behaviour being more enhanced at higher oxidation potentials, due to the stronger oxidising conditions imposed.

Organic modifier concentration is one of the main parameters that control retention, selectivity and resolution in a chromatographic separation. Therefore, the effect of methanol on the background current at different potentials was also studied. The effect of methanol was found to be less pronounced than the one of acetate, and the slight increase with methanol concentration could be due to an higher solute mobility, caused by the reduced dimensions of ions that become less hydrated as methanol content increases, and to the change of the apparent $\mathrm{pH}$ of the eluent. The lower conductivity brought by the increase of viscosity when methanol is added in the mobile phase (at least up to $50 \% \mathrm{v} / \mathrm{v}$ [19]) seems to play a less effective role. The results obtained, shown in figure $1 \mathrm{~B}$, suggest that methanol concentration could be easily varied to con- trol the efficiency of separation without significantly loosing neither on baseline stability nor on the sensitivity of the determination.

The increase of the flow rate gives rise to an increase in the baseline, as it will be shown in the next section.

These observations show that the background signal of the detector increases with applied potential, flow rate and eluent complexity (i.e. the number, kind and concentration of the eluent components). Therefore it is convenient to wait for baseline stabilisation before running a chromatographic separation whenever some parameter is changed. The time required for stabilisation depends on the applied potential: the baseline is stable after 15 and 30 minutes at 500 and $700 \mathrm{mV}$ respectively, whereas some occasional fluctuations of about $100 \mathrm{nA}$ are still observed after two hours at $900 \mathrm{mV}$. Such fluctuations appeared even after twelve hours of conditioning. These information on the effect of various parameters on the baseline signal and on the conditions for lowering its fluctuations should be kept in mind when using amperometric detectors especially when trace determinations are performed;

- current/potential curve: before running a chromatographic separation it is advisable to obtain a current/potential curve for each analyte by measuring the peak heights or areas at different oxidation or reduction potentials, in order to identify the best value for detection.

This last procedure was followed for hydroquinone $\left(k^{\prime}\right.$ $1.0)$, which is easily oxidised to quinone when the proper cell potential is applied. As figure 2 shows, the signal from hydroquinone appears at potentials more positive than $-100 \mathrm{mV}$ and reaches a plateau at $100 \mathrm{mV}$. The signal remains stable up to $500 \mathrm{mV}$. Any potential in the range $100-500 \mathrm{mV}$ is suitable for its determination. Such a broad plateau can be exploited in order to mask hydroquinone with respect to less easily oxidisable solutes (see below). The following experiments with hydroquinone were performed at $500 \mathrm{mV}$;

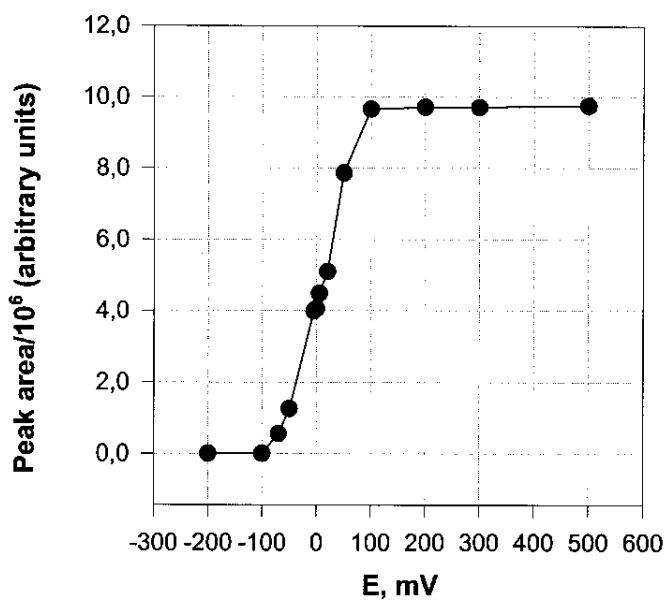

Fig. 2. Current-potential curve for hydroquinone. Mobile phase: $\mathrm{H}_{2} \mathrm{O} / \mathrm{CH}_{3} \mathrm{OH} \quad 85 / 15 \quad(\mathrm{v} / \mathrm{v})$ containing $100 \quad \mathrm{mM}$ $\mathrm{CH}_{3} \mathrm{COOH} / \mathrm{CH}_{3} \mathrm{COONa}$ (pH 4.75). Hydroquinone concentration $0.5 \mathrm{mg} \mathrm{L}^{-1}$. Oxidation potential: $500 \mathrm{mV}$. 
- linearity, repeatability, detection limit: solutions containing 10, 50, 100, 200 and $500 \mu \mathrm{g} \mathrm{L} \mathrm{L}^{-1}$ of hydroquinone were sequentially injected and the signal of the first electrode was recorded. The response (peak area) linearity was very good (correlation coefficient 0.998 ) as well as the repeatability, which ranged from 0.1 to $2.5 \%$ for concentrations $\geq 50 \mu \mathrm{g} \mathrm{L}^{-1}(n=5)$; the relative standard deviation was higher $(12.0 \%)$ at $10 \mu \mathrm{g} \mathrm{L}^{-1}$ level. Anyway this results are acceptable taking into account the low concentration involved. The analyte peak obtained from a freshly prepared $0.5 \mathrm{mg} \mathrm{L}^{-1}$ solution was found to be about $20 \%$ higher than the one obtained from the same solution 24 hours later, owing to the instability of hydroquinone, which is easily oxidised by air oxygen $\left(E^{\circ}=\right.$ $0.699 \mathrm{mV}$ [20]). Therefore the test solutions were freshly prepared daily. A decrease in sensitivity was observed after some months of extensive use, but the detector performance could be restored after a drastic treatment with $6 \mathrm{~N}$ nitric acid, as advised by the manufacturer. Anyway such treatment must be performed only when strictly necessary in order to extend cell lifetime.

A detection limit of $5 \mu \mathrm{g} \mathrm{\textrm {L } ^ { - 1 }}$ for hydroquinone was estimated as three times the background signal;

- dual electrode configuration: the detector cell is equipped with two working electrodes. The first one has large size and surface area and works in the coulometric mode, i.e. a quantitative electrolysis of the electroactive substance is obtained in less than $100 \mathrm{~ms}$. The second working electrode has smaller size and surface area and works in the amperometric mode, i.e. only a percentage of the solute is reduced or oxidised, so it is expected to give a lower response, i.e. smaller peak areas. Experiments with hydroquinone showed that the coulometric signal to noise ratio was about twice as large as the amperometric one.

This configuration allows the use of the first electrode as a screen for interfering substances. If two solutes with different redox potentials are chromatographically not well separated, the one with the lowest oxidation (or highest reduction) potential can be quantitatively oxidised (or reduced) at the first electrode, so that the current measured at the second electrode is due only to the other solute. It is usually advisable to work with the first electrode, which gives higher signal to noise ratio, and to use the second one in case a screen against interfering substances is necessary.

\section{Bulk and flow electrolysis}

Voltammetric techniques involve the redox reaction of a very small percentage of the analytes at a microelectrode. On the other hand in bulk electrolysis processes the electroactive species are quantitatively oxidised (or reduced) at the electrode, which has a large surface area. The solution is usually stirred, in order to maintain a diffusion layer as thin as possible. Typical techniques based on bulk electrolysis are amperometric and coulometric titrations, coulometry as well as electrosynthesis and electrodeposition.

In controlled potential electrolysis the redox current decreases with time according to [21]:

$$
\frac{i_{\mathrm{t}}}{i_{\mathrm{t}_{0}}}=\exp \left[-\left(\frac{D A}{V \Delta}\right) t\right]
$$

where

$i_{\mathrm{t}}=$ current at time $t$

$i_{\mathrm{t}_{0}}=$ initial current

$D=$ diffusion coefficient

$A=$ electrode area

$V=$ solution volume

$\Delta x=$ diffusion layer thickness.

In flow electrolysis the solution flows through the electrochemical cell containing a porous working electrode. This technique can be applied when the iR drop inside the pores is small, the redox kinetics is fast and the efficiency is quantitative. Flow electrolysis techniques are applied in continuous monitoring of electroactive species.

Both processes of bulk and flow electrolysis can take place at the first electrode of the Coulochem detector, if the proper conditions are established. In fact the area of such electrode allows virtually quantitative electrolysis to occur and the size of the electrode pore channels and the cell volume are quite small, so that the diffusion layer is minimized (its maximum thickness is half the pore width) and its value can be considered constant, as in stirred solutions. Therefore the possibility of applying the theory of bulk and flow electrolysis to the detector was examined.

- Bulk electrolysis: a bulk electrolysis was performed by injecting a solution containing $2 \mathrm{mg} \mathrm{L}^{-1}$ of hydroquinone in $20 \mathrm{mM} \mathrm{NaCl}$ (in order to have electrical conductivity) in the cell. After stopping the flow, the potential was instantaneously set to $500 \mathrm{mV}$ and the current vs. time response was recorded (straight curve in Fig. 3). Equation (1) was fitted, by iterative non linear regression of experimental current values, in the form:

$$
i_{\mathrm{t}}=a \times \exp \left(-k_{1} t\right)+b \times \exp \left(-k_{2} t\right)+c
$$

where the total current was split in two contributions, due to the analyte and the background respectively, and a constant offset $\mathrm{c}$ taking into account the instrumental noise was added. Table I reports the values obtained for the parameters, which allowed to calculate the theoretical trend (dotted curve in Fig. 3). As it can be seen, the

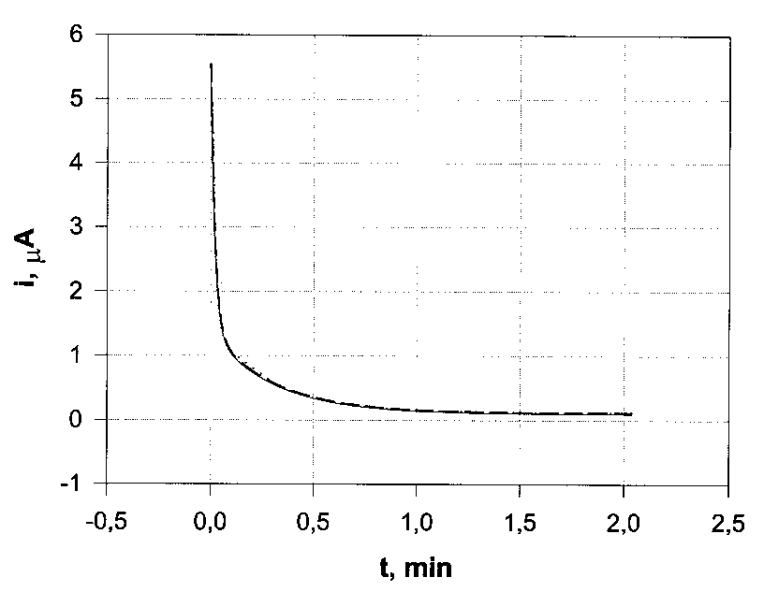

Fig. 3. Experimental (straight curve) and calculated (dotted curve) current-time response for bulk electrolysis of $2 \mathrm{mg} \mathrm{L}^{-1}$ of hydroquinone in $20 \mathrm{mM} \mathrm{NaCl}$. Oxidation potential: $500 \mathrm{mV}$. 
Table I. Values of the parameters obtained by iterative non linear regression of equations (2) and (7).

\begin{tabular}{lccccc}
\hline & $a$ & $b$ & $c$ & $k_{1}$ & $k_{2}$ \\
\hline Equation 2 (bulk electrolysis) & 1.27 & 4.165 & 0.118 & 3.33 & 48.36 \\
Equation 7 (flow electrolysis) & & & & 33.66 & 0.24 \\
\hline
\end{tabular}

observed behaviour is in good agreement with the calculated one.

- Flow electrolysis: the process occurring during the detection of chromatographically separated species is actually a flow electrolysis.

Consider a porous electrode through which a solution

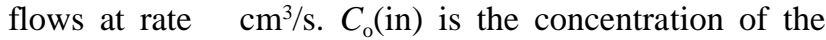
oxidised form of the solute at the inlet of the cell. In a reduction process with current efficiency $100 \%$, i.e. when the measured current is due only to the species reaction, it can be shown that [21]

$$
i=n F C_{\mathrm{o}}(\text { in }) v \exp \left(-\frac{m_{\mathrm{o}} s A \mathrm{~g}}{\mathrm{v}}\right)
$$

where

$n=$ number of exchanged electrons

$m_{\mathrm{o}}=$ mass transfer coefficient

$s=$ electrode specific area $\left(\mathrm{cm}^{-1}\right)=a / L A(a=$ total pore area, $L=$ electrode length, $A=$ electrode cross section).

Therefore the electrolysis current increases with analyte concentration, flow rate, electrode inner surface and ion mobility. It must be pointed out that coulometric efficiency is maintained at low flow rates, like typical chromatographic ones $(0.5-2.0 \mathrm{~mL} / \mathrm{min})$.

On the other hand the fraction of converted analyte $R$ is given by

$$
R=1-\exp \left(-\frac{m_{\mathrm{o}} s A L}{\mathrm{v}}\right)
$$

and increases with decreasing flow rate.

Thus a compromise must be established between high sensitivity and high reaction yield depending on the aim of electrolysis (species determination or conversion).

Flow rate and peak area: an expression was derived to relate the chromatographic peak areas signal to flow rate starting from equation (3). Assuming that the concentration profile of electroactive substance reaching the electrode after chromatographic separation has a Gaussian shape, equation (3) can be applied to any point of the Gaussian curve. If $C_{\mathrm{o}}$ (in) varies with time, the resulting current will vary accordingly, and equation (5) can be written:

$$
i(t)=n F C(t)_{(\mathrm{in})} v\left[1-\exp \left(-\frac{m_{\mathrm{o}} s A L}{\mathrm{v}}\right)\right]
$$

where $C(t)_{\text {(in) }}$ is the analyte concentration at time $t$.

Integration of the above expression between $t_{1}$ (start of the chromatographic peak) and $t_{2}$ (end of the chromatographic peak) gives

$$
\int_{\mathrm{t}} i(t) \mathrm{d} t=n F\left(\int_{t} C(t)_{(\mathrm{in})} \mathrm{d} t\right) \vee\left[1-\exp \left(-\frac{m_{\mathrm{0}} s A L}{\mathrm{~V}}\right)\right]
$$

where $\int i(t) \mathrm{d} t$ corresponds to charge $Q$, that is the area of the chromatographic peak, while $\int C(t)_{(\text {in) }} \mathrm{d} t v$ is the solute injected quantity, which has been subject to dispersion during the chromatographic separation. Therefore equation (6) can be rewritten as

$$
Q=k_{1} v\left[1-\exp \left(-\frac{k_{2}}{\mathrm{v}}\right)\right]
$$

where $k_{1}$ and $k_{2}$ are constants whose values depend on electrode, eluent and solute characteristics and concentration.

Equation (6) expresses the desired relationship between the chromatographic peak area and flow rate.

- Experimental and calculated behaviour: equation (7) was experimentally verified by injecting $0.5 \mathrm{mg} \mathrm{L}^{-1}$ of hydroquinone at different flow rates and measuring the corresponding peak areas. The values of $k_{1}$ and $k_{2}$ for hydroquinone oxidation were calculated from equation (7) by iterative non linear regression (Tab. I). The substitution of the obtained parameters in the equation proposed, made possible to calculate the predicted current values for hydroquinone electrolysis. Figure 4 shows the good agreement between the calculated and measured values.

The increase of signal with flow rate is attributed to an enhanced mass transport to the electrode.

The knowledge of $k_{1}$ and $k_{2}$ values allows to predict the signal trend for the analytes of interest and to choose the flow rate for the best detection condition. It should be pointed out that even if high flow rates provide higher sensitivity, they could negatively affect the peak shape and resolution and give rise to high backpressure in the chromatographic system. For this reason, the optimum flow rate should be a compromise between column and detector performance.

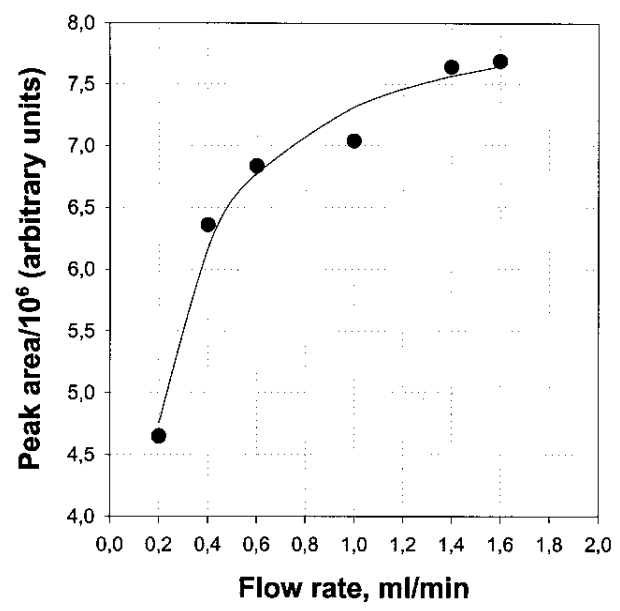

Fig. 4. Experimental and calculated relationship between peak area and flow rate. $(\bullet)=$ experimental results; $\left(\_\right)=$calculated curve. Mobile phase: $\mathrm{H}_{2} \mathrm{O} / \mathrm{CH}_{3} \mathrm{OH} 85 / 15(\mathrm{v} / \mathrm{v})$ containing $100 \mathrm{mM}$ $\mathrm{CH}_{3} \mathrm{COOH} / \mathrm{CH}_{3} \mathrm{COONa}$ ( $\mathrm{pH}$ 5.5). Hydroquinone concentration $0.5 \mathrm{mg} \mathrm{L}^{-1}$. Oxidation potential: $500 \mathrm{mV}$. 


\section{Original articles}

\section{Conclusions}

The performance and features of a chromatographic electrochemical detector were studied. The buffer has a stronger effect on the baseline than methanol, whereas formate buffer gives rise to a lower noise than equimolar acetate, probably due to a different degree of dissociation. The possibility of electrochemical exclusion of interferences was also confirmed; the dual electrode configuration of the detector cell allows to increase the system specificity by using the first electrode as a screen for easily oxidisable (or reducible) solutes.

The redox process occurring in the detector cell is represented by a flow electrolysis. Starting from the theory of electrolysis it was possible to develop an expression relating chromatographic peak areas to flow rate. The overall agreement between experimental and calculated behaviour was good.

\section{Acknowledgement}

The authors thank Ministero dell'Università e della Ricerca Scientifica and Tecnologica (MURST) and C.N.R. (Rome) for financial support.

\section{References}

1. Kissinger, P. T.; Heineman, W. R. "Laboratory Techniques in Electroanalytical Chemistry", Dekker, New York, 1996; p 813854.

2. Chen, L.; Krull, I. S. Electroanalysis 1994, 6, 1-8.

3. Stulik, K. Anal. Chim. Acta 1993, 273, 435-441.
4. Achilli, G.; Cellerino, G. P.; Melzi d'Eril, G. V.; Tagliaro, F. J. Chromatogr. A 1996, 729, 273-277.

5. Solbrig-Lebuhn, H. LaborPraxis 1992, 16, 786-789.

6. Li, Z. L.; Mou, S. F.; Ni, Z. M.; Riviello, J. M. Anal. Chim. Acta 1995, 307, 79-87.

7. Bond, A. M.; Wallace, G. G. Anal.Chem. 1981, 53, 1209-1213.

8. Lihl, S.; Rehorek, A.; Petz, M. J. Chromatogr. A 1996, 729, 229-235.

9. Palumbo, G.; Carlucci, G.; Mazzeo, P.; Frieri, G.; Pimpo, M. T.; Fanini, D. J. Pharm. Biomed. Anal. 1995, 14, 175-180.

10. Corradini, C.; Corradini, D.; Huber, C. G.; Bonn, G. K. Chromatographia 1995, 41, 511-515.

11. Schmidt, D.; Roznoski, M.; Ebert, M. H. Biomed. Chromatogr. 1990, 4, 215-220.

12. Sarzanini, C.; Mentasti, E.; Nerva, M. J. Chromatogr. A 1994, 671, 259-264.

13. Paterson, B.; Cowie, C. E.; Jackson, P. E. J. Chromatogr. A 1996, 731, 95-102.

14. Achilli, G.; Cellerino, G. P.; Melzi-d'Eril, G.; Bird, S. J. Chromatogr. A 1995, 697, 357-362.

15. Hojabri, H.; Lavin,A. G.; Wallace, G. G.; Riviello, J. M. Anal. Chem. 1987, 59, 54-57.

16. Zhou, J.; Zhang, L.; Wang, E. J. Chromatogr. Biomed. Appl. 1993, 130, 103-109.

17. Poole, C. F.; Poole, S. K. Chromatography Today, Elsevier, Amsterdam, 1991.

18. Haddad, P. R.; Jackson, P. E. Ion Chromatography principles and applications, Elsevier, Amsterdam, 1990.

19. Colin, H.; Diez-Maza, J. C.; Guiochon, G.; Czajkowska, T.; Miedziak, I. J. Chromatogr. 1978, 167, 41-65.

20. Skoog, D. A.; Leary, J. L. Principles of Instrumental Analysis, Saunders College Publishing, Orlando, 1992; p 700.

21. Bard, A. J.; Faulkner, L. R. Electrochemical Methods, Wiley and Sons, New York, 1980; p 370. 